\title{
Factors in use of family planning services by Syrian women in a refugee camp in Jordan
}

\author{
Lucy West, ${ }^{1}$ Harriet Isotta-Day, ${ }^{2}$ Maryam Ba-Break, ${ }^{3}$ Rosemary Morgan ${ }^{4}$
}

\begin{abstract}
${ }^{1}$ Foundation Doctor, West Hertfordshire Hospitals NHS Trust, Watford General Hospital, Watford, UK

${ }^{2}$ Foundation Doctor, North Bristol NHS Trust, Southmead Hospital, Bristol, UK

${ }^{3}$ Teaching Fellow in International Public Health, Nuffield Centre for International Health and Development, University of Leeds, Leeds, UK

${ }^{4}$ Research Fellow in International Health, Department of International Health, Johns Hopkins Bloomberg School of Public Health, Baltimore, MD, USA
\end{abstract}

\section{Correspondence to}

Dr Lucy West, West Hertfordshire Hospitals NHS Trust, Watford General Hospital Watford WD18 OHB, UK; lucywest5@doctors.org.uk

Received 9 July 2014 Revised 15 November 2015 Accepted 31 January 2016 Published Online First 9 March 2016

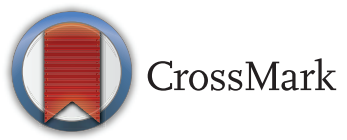

To cite: West L, Isotta-Day H, Ba-Break M, et al. J Fam Plann Reprod Health Care 2017:43:96-102.

\begin{abstract}
Background The Syrian conflict presents the fastest growing refugee crisis in the world today, with over four million people now displaced outside the country. Existing literature suggests that family planning services are often still neglected in crisis response efforts.

Methods A small-scale qualitative study conducted in May 2013, interviewing Syrian women residing in a Jordanian refugee camp about use and barriers to accessing family planning services.
\end{abstract}

Results The study shows that significant barriers remain, and suggests that international attempts to address refugees' family planning needs remain inconsistent.

Conclusions Several practical measures are identified to address barriers to access, making the article of both practical and academic relevance.

\section{INTRODUCTION}

The World Health Organization estimates that 222 million women around the world have an unmet need for family planning (FP). ${ }^{1}{ }^{2}$ Providing FP services for these women could present a costeffective way to reduce global maternal mortality by $32 \%$, and childhood mortality by almost $10 \% .^{2-4}$

Refugees are particularly susceptible to reduced access to FP due to an absence of health services, loss of social support networks, and low prioritisation of FP services in crisis response programmes. ${ }^{5-8}$ The specific reproductive health needs of refugees were recognised during the 1994 International Conference on Population and Development. ${ }^{5}$ Since then the Inter-Agency Working Group on Refugee Reproductive Health (IAWG) and other organisations have been working to increase access to FP services

\section{Key message points}

- Family planning (FP) services were available; however, barriers to service uptake included poor awareness of FP services, overburdened health services, cultural pressures regarding fertility, and poorly trained service providers.

- These barriers are well recognised in existing research, with evidence to suggest that interventions to address them have been successfully implemented in other refugee settings. This suggests that despite recognition, such interventions have yet to be implemented consistently.

- Future research is needed into effective methods for international dissemination of evidence for established interventions in FP and how to adapt such interventions in different refugee settings.

for refugees through the use of policies and programmes like the Minimum Initial Service Package (MISP) for reproductive health in crises. ${ }^{5-11}$

The Syrian conflict is currently the largest refugee crisis in the world. In August 2015 it was estimated that over four million people were externally displaced; 628000 of whom were residing in Jordan. ${ }^{12}$ Approximately $20 \%$ of those refugees living in Jordan reside in purpose-built camps and there is limited evidence to indicate the efficacy of FP service provision within these camps. ${ }^{13}$

The aim of this study was to explore what factors facilitated or limited use of FP services in a Syrian refugee camp in Jordan, in order to identify areas for future research and intervention. 


\section{METHODS}

\section{Design setting}

In May 2013, semi-structured interviews were conducted with 16 Syrian women, residing in one refugee camp in Jordan. At the time of the study, the camp was the largest in the world for Syrian refugees, housing over 140000 of the estimated 500000 Syrian refugees registered or awaiting registration with the United Nations High Commissioner for Refugees (UNHCR) in Jordan. ${ }^{14}{ }^{15}$ An estimated 53\% of these refugees were female, with the majority aged between 18 and 35 years old. ${ }^{15}$ Within the camp, three general health centres and one reproductive health centre were providing FP services free of charge, including contraceptive methods such as the oral contraceptive pill (OCP), intrauterine device (IUD), condoms and injections. Camp inhabitants were not permitted to leave the camp unless referred for emergency medical procedures and, as a result, could not access Jordanian FP services.

\section{Sample}

A national non-governmental organisation (NGO) provided initial access to potential participants in the camp. A 'snowball' technique was used with women spreading information about the study by word of mouth. Women who met the inclusion criteria were selected to participate. ${ }^{16}$ To ensure ethical and cultural appropriateness, study participants included women who were of reproductive age, over 18 years old and married. ${ }^{17} 18$ Women who had given birth in the camp in the last year were selected to participate as women have a particularly high need for FP during the postpartum period, when inadequate birth spacing can have harmful health impacts on both mother and child. ${ }^{19}$ Moreover, as pilot interviews and key informants suggested that use of FP services in the camp was relatively low, this criteria facilitated the process of identifying potential participants with FP needs and meant that participants were able to comment on the quality of the reproductive health services they had experienced as a result of giving birth in the camp.

The sample size was determined by the number of women who met the inclusion criteria and who agreed to be interviewed, and project resource constraints.

Participants ranged in age from 18 to 43 years. Most were from Daraa, a province in Southern Syria that borders Jordan. Six had one child, while the rest had more than three. At the time of the study, all participants lived with their husbands in the camp, apart from one whose husband had returned to Syria shortly before the study. All had completed a minimum of elementary school education.

\section{Data collection}

A question guide was used to conduct the interviews, which was developed from the IAWG recommendations for implementation of FP services in humanitarian settings, ${ }^{20}$ and themes identified in existing literature concerning refugee FP services. Topics discussed included awareness of the concept of FP and contraceptive methods, previous or current use of FP methods, access to camp services, service quality, barriers to use and potential improvements. Predetermined prompts and explanations were used if participants did not understand or were not forthcoming about a topic.

Interviews were conducted in participants' tents or caravans and lasted 40-60 minutes. Most participants had children present during interviews and some participants asked for a female friend to be present. No males were present during interviews.

Interviews were led by the researcher in English, translated into Arabic by an interpreter, and the participant's responses were then translated back into English. Interviews were audio-recorded and transcribed. A sample of transcripts was back-translated to ensure translation accuracy. Data were supplemented by observations and discussions with key informants in the camp.

\section{Analysis}

Findings were analysed using framework analysis. ${ }^{21} \mathrm{~A}$ thematic framework was developed from a priori themes in the question guide and emerging themes from interviews, and the data were manually analysed within this framework. ${ }^{21}$

\section{Ethics}

Full ethical approval was obtained from the Leeds Institute of Health Sciences at the University of Leeds, Leeds, UK, prior to commencing the study. Participation was voluntary and information sheets and consent forms were provided in written and spoken Arabic for all participants. Written consent was obtained from all study participants.

\section{FINDINGS}

\section{Awareness of FP methods and services}

All participants associated the term FP with modern contraceptive methods, and the majority was aware of several methods:

"I used condoms ... and I know that some women use
pills and coils [IUDs], and injections." [Participant 14]

The belief that FP is good for maternal and child health was expressed by several participants. However, concerns about the possible side effects of contraceptives were common and influenced some participant's decisions about using them:

\footnotetext{
"We believe that after the first child it's preferable ... not to have [unspecified] contraception methods because we think ... maybe we won't be able to have more children ... Some women have been sterile after they used contraception." [Participant 7]

"They said it [the OCP] might cause me not to have children anymore." [Participant 6]
} 
Despite the majority of participants displaying substantial knowledge of general health services in the camp, poor awareness and inaccurate information about FP services was common and affected access to contraceptives:

\section{"The most important [problem] is that people don't know about the contraceptive methods and where to get them..."}

"I don't know if there are any kinds of [FP] services here and where ... no one told me .... nobody cares." [Participant 9]

Participants predominantly obtained information about FP from female friends and family in personal social networks, both in the camp and previously in Syria. Information shared in these networks normally arose from personal experiences:

"When women gather they talk about these things [FP] so I know about those things from neighbours and family... my sister told me about condoms and we started to buy condoms afterwards.” [Participant 13]

The majority of participants stated that no health worker in the camp had ever initiated discussion about FP services with them. According to several participants, it was possible to obtain such information if they requested it themselves, for example during antenatal or childhood vaccination appointments. A few participants had heard of FP awareness campaigns, organised by NGOs in the camp, but none had attended them as they were too busy:

"I hear about campaigns ... but I don't feel there is a priority to go to these campaigns to know about them because I have to take care of my family." [Participant 16]

The majority of participants believed that providing more information about the benefits of FP and available services in the camp was important:

"If they [doctors] talk more [about FP] I would benefit from them but they don't talk, so I don't ask." [Participant 1]

"The most important thing for them [doctors] to do is ... counselling and advising when they [women] go to the hospitals and clinics here." [Participant 11]

\section{Utilisation and accessibility of FP services}

The majority of participants had not used FP counselling or contraceptive services in the camp. Several participants were using exclusive breastfeeding as a FP method:

"I know that my period will not come until he [the baby] is 8 or 9 months ... and then I will start using condoms." [Participant 13]

Most participants who had accessed FP services were older women, with more than one child. They reported obtaining IUDs and condoms. Of the participants not using FP, those with more than one child were more likely to want to use FP in the near future. The participant whose husband had returned to Syria stated that his absence was her reason for not using FP at the time of the study.

In comparison to FP services, participants had used a range of other reproductive health services in the camp. All had delivered their last child in a health facility, most had attended at least one antenatal check-up, and several had undergone postnatal checkups. According to the participants that were aware of what FP services were available in the camp, FP could be obtained at several general health centres and one specific reproductive health centre. They repeatedly mentioned that overwhelming demand for various health services at these centres presented a barrier to accessing FP services:

\section{"Services are provided but they are way too crowded, maybe you have to wait for 2 hours and there might be 100 women before you." [Participant 5]}

Health centres reportedly attempted to manage high service demand by offering consultations according to the immediate needs of users. Participants suggested that this limited access to FP consultations, as they were considered a low priority compared to consultations for pregnant or acutely unwell patients.

Participants felt this issue could be addressed by running women-only clinics that separated the provision of FP services from other health services. This would ensure that FP consultations were not neglected as women would not have to compete for consultations with other camp inhabitants with different health needs. Participants suggested that such clinics could also make FP more accessible because some felt too shy to ask for contraceptives in a general health service environment where male patients or staff could be present. As the reproductive health centre in the camp predominantly served women it could provide a good location for such clinics.

\section{Cultural acceptability of FP services}

The majority of participants iterated that FP was a culturally acceptable practice, both in Syria and in the camp, with many stating they would like to use FP at some point:

\section{"I think it would be better if I had planned births actu- ally, because I want to have better health for myself and to take good care of my children." [Participant 6]}

Having enough time to care for each child adequately and preventing pregnancy when families could not afford to support another child were considered important reasons for FP use. Several participants who had not been interested in FP in the past were considering using it in the camp: 
"The situation in the camp is really difficult ... milk, diapers, clothes for the babies ... everything is expensive, so our lives are really getting harder... I'm not thinking about having another baby now." [Participant 13]

Conflicting ideas emerged about the attitudes of husbands and families. Half the participants believed that their husbands supported the use of FP, while half stated that their husbands were unsupportive, however, the impact of these attitudes on FP access was unclear:

"He [husband] told me not to put [the IUD in], he wants more children ... but I am going to do it without his permission. I am going alone to put it [in] ...” [Participant 1]

"Men need to hear about this [FP] even more than the women, because they control ... this whole children thing." [Participant 1]

Several participants believed support for FP had been growing amongst Syrians, particularly within younger generations, since before the conflict. However, several participants reported that traditional attitudes towards childbearing in Syria were less supportive of FP:

"People don't like to talk about this [FP] because it's in their heads that they should have a lot of babies, so it's not ... a common subject in Syria." [Participant 1]

This theme was reinforced by younger participants who felt that they did not want to use FP as they wanted more children, despite living in the camp.

\section{Quality of services}

As participants had minimal experience of using FP services in the camp, when exploring their beliefs about which factors influenced the quality of services they were asked about their experiences of general health services in the camp not just FP. Staff gender was an important factor:

"When I came to the camp I was worried how I would deliver and if there were any men during the delivery ... but then I was really happy when I found out they were all women." [Participant 11]

"[X] hospital is best ... they have only women doctors ... I would go there if I wanted family planning." [Participant 5]

Participants felt in order to improve service quality staff required training on conducting intimate examinations and consultations in a respectful manner:

"They were not that respectful ... they were yelling or were rude to me, and when the male doctors came I was really shy and didn't like that they came and they saw me and they didn't care that I was uncovered." [Participant 15]

"[If] I needed any kind of [FP] counselling ... I prefer not to go ... they're not respectful to me.” [Participant 9]

\section{DISCUSSION}

\section{Main findings}

Despite good awareness of modern contraceptives, misconceptions about side effects and poor knowledge of available services presented a significant barrier to uptake of FP. Although some participants had heard of awareness campaigns in the camp, none had attended them and targeting women during other reproductive health care appointments could provide a more effective way of disseminating information. Another significant barrier to accessing FP in the camp was the low prioritisation of FP consultations by both general health service providers and participants, as a result of overburdened health services. This pressure on health services is challenging to address due to the continuous influx of new refugees and shortfalls in funding. ${ }^{9} 1422$ Participants felt that the presence of female staff increased uptake of FP services but disrespectful staff conduct reduced uptake, and better staff training regarding cultural sensitivity was required to address this issue.

Participants believed that people generally supported the idea of FP, both in Syria and in the camp. However, traditional cultural attitudes towards fertility were found to reduce uptake of FP amongst younger participants. Conflicting spousal attitudes reflected these cultural influences; however, it was difficult to determine the extent to which this affected participants' abilities to access FP. Findings suggested that harsh conditions in the camp could encourage the uptake of FP.

\section{What is already known and what this study adds} Donati et al.'s $\mathrm{s}^{23}$ study in Gaza found that $55 \%$ of 800 refugee women interviewed were not using FP primarily as a result of poor knowledge and misconceptions about side effects. Misconceptions about contraceptive side effects are widespread in the Middle East. ${ }^{4}{ }^{24}$ Participants in this study exhibited a good basic level of knowledge about FP from their experiences in Syria, where the government has previously directly supported policies on access to contraception and preconflict contraceptive prevalence rates were reported to be around 54\%. ${ }^{17}$ However, certain misconceptions still existed, suggesting that FP promotion in the camp could be more effective if specifically targeted towards eradicating myths about side effects and signposting services. Components of a recent IAWG global review of progress in providing reproductive health care for refugees found that poor awareness of available services limited the uptake of FP in multiple settings and that increased educational outreach was needed..$^{9} 10$ In terms of improving FP awareness amongst refugees in the future, determining the extent and methods of FP education that refugees experienced before displacement could improve the efficacy of FP awareness campaigns by ensuring they are targeted appropriately. 
Howard et al.'s ${ }^{25}$ study, involving Sierra Leonean and Liberian refugees in Guinean camps, found that women who had given birth in the camps at least once before had access to FP information via antenatal consultations and were significantly more knowledgeable about FP than those who had not attended antenatal consultations. ${ }^{25}$ Providing FP counselling during antenatal and postnatal consultations could, therefore, provide an effective means of improving uptake.

High service demand and funding limitations have been identified previously as barriers to FP access for refugees. ${ }^{26}$ Existing literature suggests this issue is particularly relevant for FP services as they do not fall neatly into the remit of emergency relief or long-term development projects and can subsequently be neglected. ${ }^{1127}$ McGinn et al. ${ }^{27}$ conclude that including refugee reproductive health needs in long-term national and donor health and development plans can help to co-ordinate and sustain funding for services more effectively. The potential exists for integrated planning of this sort with the Jordanian government; however, this would more likely focus on Syrian refugees residing outside camps in Jordan as they are permitted to access public Ministry of Health FP services. ${ }^{9} 14$

As regards cultural attitudes, reports by Roudi-Fahimi ${ }^{28}$ and DeJong et al. ${ }^{29}$ concerning reproductive health data in the Middle East, indicated that considerable cultural pressure is placed on young women to begin childbearing early and have multiple children. This phenomenon is increasingly important as the prevalence of early marriages has risen amongst Syrian refugees. ${ }^{30}$ Improving awareness of the benefits of FP could help tackle this issue and encourage women to prioritise their FP needs. Findings suggest that if reproductive health staff encouraged such discussion amongst women it would spread via social networks and women may be more receptive to such messages while living as refugees.

In the context of this study the host nation, Jordan, has a similar culture, language and religion to that of the refugees in the camp, which may have reduced barriers in providing FP services. However, this may be an important consideration in other refugee contexts. Regarding spousal attitudes, Roudi-Fahimi et al.'s ${ }^{4}$ report on the need for FP in Arab countries indicated that the majority of Syrian women made decisions about FP jointly with their husbands; however, $27 \%$ stated that their husbands had the final say, implying that targeting men with FP education is essential to improving access.

The IAWG reproductive health field manual suggests that having staff of the same gender as service users is essential to providing culturally sensitive care and increasing FP uptake. ${ }^{20} \mathrm{~A}$ recent evaluation of implementation of the MISP in Jordan reported that a lack of female staff acted as a barrier to FP access for Syrians. ${ }^{9}$ In Howard et al.'s ${ }^{25}$ study in Guinea, female refugees who were trained midwives established their own service in response to inappropriate reproductive health services, which was effective at improving FP awareness and uptake. Recruitment of qualified female refugees in the camp in Jordan, or training of unqualified female refugees, could provide a cost-effective way to increase the prevalence of female FP providers while improving local capacity. Although refugees are not legally allowed to work in Jordan, within the camp they are permitted to do volunteer work for NGOs, which could provide an important opportunity to empower refugees. Training to improve staff conduct and communication is also supported by the findings of the MISP evaluation in Jordan, and Tran et al. suggest that accountability for staff conduct is important for service improvement. ${ }^{9} 11$

\section{Limitations}

Using a national NGO to gain initial access to the camp and potential participants may have affected responses and resulted in sampling bias. Purposive sampling, for example of older and younger participants, was not possible due to limited project capacity, the lack of communication systems in the camp and the transient nature of camp residents. For similar reasons, it was not feasible to follow up with participants after initial interviews. Interviewing refugees living outside of the camp was also beyond the scope of this project; this presents an important future research opportunity as these refugees likely face different issues such as the cost of obtaining services.

The inclusion criteria meant that women who had not accessed any reproductive health services in the camp were not included in the study. Furthermore, the opinions of newly married women without children were not included, and numerous participants were still exclusively breastfeeding at the time of the study, which impacted on the extent to which they had contemplated the use of other FP methods.

The fact that most participants had children, and some had a female friend, present during interviews may have affected responses. While quotes were used to illustrate the findings, conducting interviews via an interpreter means that conclusions cannot be drawn from the exact phrasing used.

\section{CONCLUSIONS}

This study explored what factors facilitated or limited use of FP services by Syrian women in a refugee camp in Jordan. The study found that various FP services were provided in the camp, however, there was potential to increase uptake of these services by addressing barriers such as poor awareness of FP services, overburdened health services and inappropriate staff conduct.

Improvements in awareness and the cultural acceptability of services could be achieved through better training for reproductive health staff, particularly in relation to asking women about their FP needs and respectful behaviour, and the recruitment of more 
female staff to provide FP services. Targeted FP education, for example for younger women and men, could help to increase FP uptake by alleviating cultural pressures regarding fertility. In addition, reorganising clinics and recruiting refugees to provide services could help to address service demands within funding constraints.

The barriers identified to accessing FP in this study are well recognised in existing research, with evidence to suggest that interventions to address such barriers have been successfully implemented in other refugee settings around the world. Some of these interventions, such as providing same gender staff, have even been incorporated into refugee reproductive health response protocols like the IAWG field manual. The persistence of these barriers, therefore, suggests that research to evaluate interventions is limited, dissemination of evidence about successful interventions has not been effective or, despite the availability of such evidence, it has not been incorporated consistently into the planning and provision of FP services in the Jordanian context. ${ }^{31}$

Further research is therefore warranted into methods for disseminating evidence of established interventions in FP and implementing such interventions in different refugee settings.

Acknowledgements This project would not have been possible without the assistance of Farah Jukhadar, Muzna Hasnawi, Nicola West, Steven Moore and the Syrian Women's Association, Jordan.

Funding This work was supported by non-project-specific funding from the Alumni Footsteps Fund, which is supported by donations from former students and friends of the University of Leeds.

Competing interests None declared.

Ethics approval Ethical approval for the project was obtained from the Leeds Institute of Health Sciences at the University of Leeds and all procedures followed during the study were in accordance with the ethical standards of the Helsinki Declaration $(1964,2008)$ of the World Medical Association.

Provenance and peer review Not commissioned; externally peer reviewed.

\section{REFERENCES}

1 World Health Organization. Fact Sheet No. 351. Family Planning. 2013. http://www.who.int/mediacentre/factsheets/ fs351/en/index.html [accessed 16 July 2013].

2 Cleland J, Bernstein S, Ezeh A, et al. Sexual and Reproductive Health 3 - Family planning: the unfinished agenda. Lancet 2006;368:1810-1827.

3 Singh S, Darroch J. Adding It Up: Costs and Benefits of Contraceptive Services - Estimates for 2012. Guttmacher Institute and United Nations Population Fund, 2012. http:// www.guttmacher.org/pubs/AIU-2012-estimates.pdf [accessed 16 July 2013].

4 Roudi-Fahimi F, Abdul Monem A, Ashford L, et al. Women's Need for Family Planning in Arab Countries. Washington, DC: Population Reference Bureau, 2012.
5 Krause S, Jones R, Purdin S. Programmatic responses to refugees' reproductive health needs. Int Fam Plan Perspect 2000;26:181-187.

6 McGinn T. Reproductive health of war-affected populations: what do we know? Int Fam Plan Perspect 2000;26:174-180.

7 DeLargy P, Alakbarov R. Thinking ahead about reproductive health: contingency planning and emergency preparedness in crisis situations (Iraq and West Africa). Disasters 2004;28:340-350.

8 Chi PC, Urdal H, Umeora OU, et al. Improving maternal, newborn and women's reproductive health in crisis (Protocol). Cochrane Database Syst Rev 2015;8:1-26.

9 Krause S, Williams H, Onyango MA, et al. Reproductive health services for Syrian refugees in Zaatri Camp and Irbid City, Hashemite Kingdom of Jordan: an evaluation of the Minimum Initial Services Package. Confl Health 2015;9(Suppl. 1):S4.

10 Chynoweth SK. Advancing reproductive health on the humanitarian agenda: the 2012-2014 global review. Confl Health 2015;9(Suppl. 1):I1.

11 Tran N-T, Dawson A, Meyers J, et al. Developing institutional capacity for reproductive health in humanitarian settings: a descriptive study. PLoS ONE 2015;10.

12 United Nations High Commissioner for Refugees (UNHCR). Syrian Refugees Inter-Agency Regional Update. Geneva, Switzerland: UNHCR, 2015.

13 United Nations High Commissioner for Refugees (UNHCR), UNICEF, World Food Programme (WFP). Joint Assessment Review of the Syrian Refugee Response in Jordan. Geneva, Switzerland: UNHCR, 2014.

14 United Nations High Commissioner for Refugees (UNHCR). Syria Regional Response Plan: January to June 2013. Geneva, Switzerland: UNHCR, 2013.

15 United Nations High Commissioner for Refugees (UNHCR). Weekly Inter-Agency Situational Report - JORDAN. Syrian Refugee Response Update: 26 May to 08 June 2013. Geneva, Switzerland; UNHCR, 2013.

16 Green J, Thorogood N. Qualitative Methods for Health Research. London, UK: SAGE Publishing, 2004.

17 Roudi-Fahimi F. Islam and Family Planning. Washington, DC: Population Reference Bureau, 2004.

18 Roudi-Fahimi F, Abdul Monem A. Unintended Pregnancies in the Middle East and North Africa. Washington, DC: Population Reference Bureau, 2010.

19 USAID. Statement for Collective Action for Postpartum Family Planning. 2012 http://www.mchip.net/node/1273 [accessed 12 July 2013].

20 Inter-Agency Working Group on Reproductive Health in Crises. Inter-Agency Field Manual on Reproductive Health in Humanitarian Settings: 2010 Revision for Field Review. 2010. http:/www.who.int/reproductivehealth/publications/ emergencies/field_manual/en/ [accessed 12 July 2013].

21 Ritchie J, Spencer L. Qualitative data analysis for applied policy research. In: Bryman A, Burgess R, (eds), Analysing Qualitative Data. London, UK: Routledge, 1994 Chapter 9; 173-94.

22 Agency for Technical Cooperation and Development. Jordan: Informing Aid Delivery in Za'atari Camp Through REACH. 2013. http://www.acted.org/en/ jordan-informing-aid-delivery-za-atari-camp-through-reach [accessed 16 July 2013].

23 Donati S, Hamam R, Medda E. Family planning KAP survey in Gaza. Soc Sci Med 2000;50:841-849. 


\section{Research}

24 DeJong J, Jawad R, Mortagy I, et al. The sexual and reproductive health of young people in the Arab countries and Iran. Reprod Health Matters 2005;13:49-59.

25 Howard N, Kollie S, Souare Y, et al. Reproductive health services for refugees by refugees in Guinea I: family planning. Confl Health 2008;2:12.

26 Bosmans M, Nasser D, Khammash U, et al. Palestinian women's sexual and reproductive health rights in a longstanding humanitarian crisis. Reprod Health Matters 2008;16:103-111.

27 McGinn T, Austin J, Anfinson K, et al. Family planning in conflict: results of cross-sectional baseline surveys in three African countries. Confl Health 2011;5:11.
28 Roudi-Fahimi F. Women's Reproductive Health in the Middle East and North Africa. MENA Policy Brief. Washington, DC: Population Reference Bureau, 2003.

29 DeJong J, Shepard B, Roudi-Fahimi F, et al. Young People's Sexual and Reproductive Health in the Middle East and North Africa. Washington, DC: Population Reference Bureau, 2007.

30 UN Women. Inter-Agency Assessment: Gender-Based Violence and Child Protection Among Syrian Refugees in Jordan, with a Focus on Early Marriage. Amman, Jordan: UN Women, 2013.

31 Casey SE. Evaluations of reproductive health programs in humanitarian settings: a systematic review. Confl Health 2015;9(Suppl. 1):S1. 